\title{
Lidil
}

Revue de linguistique et de didactique des langues

$40 \mid 2009$

La motivation pour l'apprentissage d'une langue seconde

\section{Performance orientation and motivational strategies in high-achievement language learners}

David Brown

\section{CpenEdition}

Journals

Édition électronique

URL : http://journals.openedition.org/lidil/2944

DOI : 10.4000/lidil.2944

ISSN : 1960-6052

Éditeur

UGA Éditions/Université Grenoble Alpes

Édition imprimée

Date de publication : 1 décembre 2009

Pagination : 105-121

ISBN : 978-2-84310-154-0

ISSN : $1146-6480$

Référence électronique

David Brown, « Performance orientation and motivational strategies in high-achievement language learners », Lidil [En ligne], 40 | 2009, mis en ligne le 01 juin 2011, consulté le 19 avril 2019. URL : http:// journals.openedition.org/lidil/2944; DOI : 10.4000/lidil.2944

(c) Lidil 


\title{
Performance orientation and motivational strategies in high-achievement language learners
}

\author{
David Brown*
}

\begin{abstract}
RÉSUMÉ
Le construit motivationnel est généralement perçu comme une dichotomie entre la motivation extrinsèque et la motivation intrinsèque. Par ailleurs, la majorité de la recherche en motivation pour apprendre une langue étrangère prend appui sur des données issues d'apprenants qui participent à des études de manière volontaire et qui exercent un élément de choix et de responsabilité dans l'apprentissage. En d'autres termes, ils sont intrinsèquement motivés. Les conclusions de telles études soutiennent que la motivation intrinsèque conduit à de l'apprentissage adapté. Cet article décrit une étude menée dans une école d'ingénieurs et une école d'architecture dans l'est de la France. On a évalué les orientations (envers la maitrise et envers la performance) chez des étudiants au travers d'une batterie de tests. L'étude cherchait à vérifier des résultats obtenus précédemment (Brown, 2007) qui indiquaient que les élèves ingénieurs semblent être orientés vers la performance. Une telle orientation contredit le paradigme motivationnel reçu. En effet, démontrer que le paradigme motivationnel classique est moins simple que l'on croyait contribuerait à expliquer certains comportements : certains apprenants affichent des tendances motivationnelles qui ne correspondent pas aux attentes. Ceci, à son tour, soulève la question de la légitimité d'importer vers l'enseignement français des pratiques venant d'ailleurs qui peuvent induire en erreur et même se révéler contre-productives lorsque l'on tente de les appliquer en France.

L'étude montre que les élèves ingénieurs ont obtenu de meilleurs résultats dans les exercices orientés vers la performance. Par conséquent, ces résultats tendent à confirmer les précédents (Brown, 2007).

Les implications pour les modèles motivationnels basés sur des considérations qualitatives sont discutées et les conséquences pour l'enseignement des langues au niveau universitaire en France sont abordées.
\end{abstract}

* Esstin, Université Henri Poincaré. 


\section{ABSTRACT}

Most motivational construals consist of an intrinsic motivation versus an extrinsic motivation dichotomy. In addition, the majority of L2 motivational research seems to draw its data from learners that participate in studies on a voluntary basis and who display choice and personal responsibility for learning outcomes. In other words, they display intrinsic motivation. Conclusions vastly state that adaptive learning takes place when learners are intrinsically motivated.

The present work describes a study carried out in an engineering college and in a school of architecture in Eastern France. Learning orientation preferences (mastery compared to performance) as they relate to students in the French university L2 setting were evaluated via a battery of tests. The study was intended to build further on the findings of previous research (Brown, 2007) that indicated strong evidence that typical engineering students may be characterized as performance oriented. Such an orientation is in opposition to the traditional motivational paradigm. Indeed, the argument that the accepted motivational paradigm may not be as simple as it has been previously construed is an attractive one and would go a long way towards explaining certain behaviors: some types of learner display motivational tendencies that do not correspond to mainstream expectations. This, in turn, raises the question of the legitimacy of importing wholesale into French education, foreign constructs that reveal themselves to be misleading and perhaps even counterproductive when attempts are made to implement them in France.

The engineering students faired best on the performance oriented exercises. Consequently, these findings tend to confirm the previous findings (Brown, 2007).

The possible implications for motivational models based on qualitative assumptions are discussed, and the consequences for L2 provision and teaching practice in French university language-teaching units providing languages for specialists of other disciplines are considered.

For several decades, second-language motivation has been the subject of considerable research. However, until very recently, most of the research had been carried out in Anglo-Saxon contexts, resulting in a theoretical grounding that reflects Anglo-Saxon cultural beliefs. This is a limitation on the paradigm, particularly when examining second language-learning motivation in non-Anglo-Saxon contexts; in French education, for example. Furthermore, despite attempts to extend the paradigm into a motivational continuum (Ryan and Deci, 2000), motivation is still very much construed within an essentially dichotomous framework: in short, the learner is characterised as an individualist who 
is motivated either intrinsically or extrinsically. From the Anglo-Saxon viewpoint, intrinsic motivation is adaptive and mastery-oriented, and hence desirable. Extrinsic motivation, on the other hand, is viewed as maladaptive and performance-oriented. Accordingly, it is undesirable (for an in-depth discussion on this question see Midgley et al., 2001). Even though such assumptions make sense, they do not necessarily hold true with French language learners: French cultural behaviour seems still to be based on principles that are not as centred on the individual as Anglo-Saxon culture. This is reflected in teaching and learning practices.

This article examines second language-learning motivation in a specifically French context: that of les écoles. Also, it seeks to highlight some of the factors that differentiate French second language-learning motivation from the commonly accepted paradigm. Before moving on to that, however, it may be of use to summarise the evidence there is for suggesting that the French cultural framework differs from other Western, or more specifically Anglo-Saxon cultures to the point that motivational attitudes in French language learners differ significantly from those found elsewhere.

\section{The cultural dimension}

As most previous motivational research comes from predominantly individualistic nations (that is to say nations that display high individualism, but low uncertainty avoidance -see Hofstede, 2006 and Fig. 1 below), the question as to whether France is sufficiently similar in its socio-cultural make-up for the same findings to hold has to be raised. In fact, according to Hofstede's (2006) indices of individualism and uncertainty avoidance, France is significantly lower in individualism (Fig. 1.1) and higher in uncertainty avoidance than the United States (Fig. 1.2). The implication is that social-psychological behaviours, and by that token, motivational attitudes, will not necessarily mesh with usual (Anglo-Saxon) motivational expectations. In other words, even though France may be more individualist than a nation like Japan (Fig. 1.1), it is not a wholly individualistic nation (the main six being the United States, Australia, the United Kingdom, Canada, Hungary and the Netherlands). It follows that the generally accepted motivational paradigm, based on Anglo-Saxon values, cannot fully apply to French learning culture. Furthermore, uncertainty avoidance (Fig. 1.2) is important in questions concerning learning orientations: a tendency 
to take risks through experimentation is a feature typical of mastery orientation, but is lacking in learners who are performance-oriented.

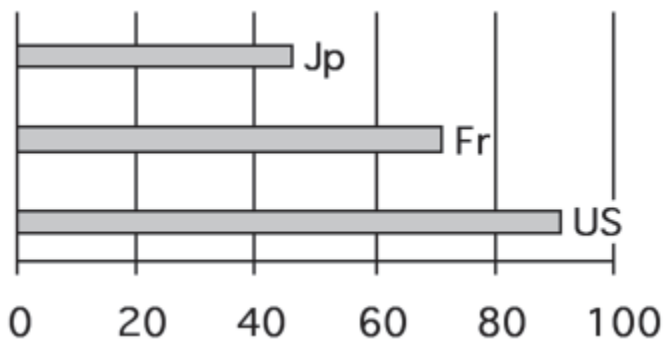

Fig. 1.1. - Individualism Index according to Hofstede (2006).

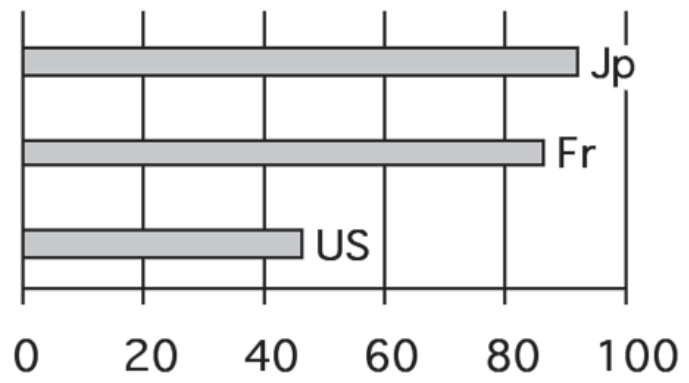

Fig. 1.2. - Uncertainty Avoidance Index according to Hofstede (2006).

\section{Achievement theory}

In the light of the above, a theoretical backdrop in motivational research that may correspond to French teaching and learning behaviours is required. Achievement goal theory seems to provide a promising framework for motivation within less individualistic contexts. The theory provides a means to describe learning in terms of two goal types: performance and mastery (Dweck, 1986). These are briefly described below.

Achievement theory has led to the characterisation of the learner not as motivated or demotivated, but as an individual motivated by and within given conditions to pursue one of two achievement goals "in a competence-relevant setting" (Midgley et al., 2001). When individuals 
desire to increase their knowledge and understanding of a subject, the goal is mastery (also learning- or task-) oriented. This goal is typically associated with individuals who show creativity in solutions, or who keep trying until they succeed. It places the accent on understanding and enquiry. When individuals focus on formally demonstrating knowledge or competence or obtaining a reward that will fuel their ego, while avoiding the dangers of trial and error, the goal is performance (also ego or ability) oriented. It places the accent on recall and memorization. Orientation towards one or the other of these two possibilities is the outward sign of divergent cognitive and affective schemata.

One of the populations taking part in the study described below comprised students in a French engineering college. Performance goal orientation suits the type of high-achievement mindset typical of such institutions. As a rule, the learners will endeavour to achieve unquestioningly, especially if reaching the goal is fuelled by the extrinsic sanctions of so-called external loci. From the language learning point of view, if clear and unavoidable objectives are set up the learners muster the effort to succeed. In other words, this characterization of French engineering students does not fit the paradigm. The majority of motivational psychologists would argue that solutions to maximise intrinsic motivation should be promoted. It is clear, however, that the educational model in French engineering colleges differs from those of the highly individualist countries like the United States. Both the organisation and teaching / learning culture in French institutions favour instrumentality and control by external loci: lecturers tend to be more directive and learners more reward oriented (working for scores, a grade, or for promotion to the next course). Accordingly, learners tend to concentrate their energy on learning facts that display performance rather than mastery. In turn, this behaviour is inherently linked to extrinsic motivation.

Would a performance-orientation motivational approach be justified in some categories of French L2 learning contexts? This seems likely. For example, a study by Brown (2002) on the use of computers in language learning uncovered positive learner-reactions to no-choice situations with preferences for imposed activities as opposed to selfchosen activities. The same study revealed enhanced vocabulary recall in no-choice students. Within mainstream motivational psychology, choice (Covington, 1992) is considered essential to intrinsic motivation and adaptive behaviour. Conversely, no-choice situations imply the presence of extrinsic influences. It is generally assumed that performance-oriented learners operate under such influences. This, of course, 
typically corresponds to the type of learning environment found in high-achievement institutions in France. Furthermore, findings from a study (Brown, 2007) on choice during listening activities led to similar conclusions about French engineering students. Choice allocation had no significant effect on motivation and, consequently, was unlikely to trigger the behaviour usually associated with mastery orientation. The question is, then, to what extent are French language-learners in highachievement institutions performance-oriented?

\section{Method}

The objective of the study was to explore motivational tendencies of French university students towards language learning as displayed via their preferences for performance orientation versus mastery orientation.

\section{Participants}

The study examined and compared two different student populations. Details common to both student populations are as follows. All students at the time of the study were aged 17 to 18 years old. The language learning groups were of mixed ability. All of the students had studied English at high school for 5 to 8 years (mean $=6.5 \mathrm{yrs}$ ). All of the students were freshmen starting a five-year study curriculum in colleges in Eastern France. Entry to the first-year of study is based on an entrance examination.

The first group was composed of engineering students $(\mathrm{N}=165)$. Studying engineering is traditionally perceived as high-achievement and reputedly draws on the "most intelligent" of high-school graduates (98\% Bac S). Entrance to the college is highly competitive: in 2007 there were 2100 candidates for 176 places offered. Class sizes for language learning were fixed at 20-24. The scores obtained on a practice TOEIC test taken during the first week of class could be described as lower intermediate $($ mean $=530 / 990)$.

The second group was composed of architecture students $(\mathrm{N}=148)$. Studying architecture is not perceived as high-achievement even though it draws students with high-school qualifications that are similar to the engineering students (80\% Bac S). With fewer students sitting the entrance exam, entry is less competitive: in 2007, there were 350 candidates for 150 places. Also, entry to the college does not entirely depend on the entry examination result; students' past record and an interview play an important role too. Again, the scores (mean=470) obtained on 
a TOEIC test taken during the first week of class correspond to lowerintermediate level. A score of 405 to 600 is the fourth level of six on the TOEIC can-do guide. In other words, the language level in both populations is largely similar.

\section{Instruments and procedure}

The analysis that follows concerns all students who took both the TOEIC test and a battery of exercises (see Appendix for examples) organised at the end of semester two ( $\mathrm{N}=141$ engineering; $\mathrm{N}=118$ architecture). Learner orientations were assessed via a use-of-English language test that took place at the end of the semester. The test included two conditions: the first comprised exercises (40 items) eliciting responses to narrowly targeted multiple-choice statements based on knowledge-based sets (Anderson et al., 2001). The second was composed of exercises (40 items) eliciting responses to broadly targeted gap-fills based on application-based statements where no set of possible answers was proposed, but were several correct responses were possible. The former group of exercises could be described as rigid or restrictive and suited to the type of cognitive processing typically found in performance-oriented learners, the latter as open or flexible and more suited to masteryoriented learners. Test content was based on a common architecture/ engineering syllabus that had been taught throughout the preceding semester. All subjects were assessed on a crossed-condition basis: to preclude any effects resulting from practice or test sequence, testing was organized so that half the subjects were assessed first in condition one then in condition two, and vice versa for the other half. Test results yielded a convenient score out of 20 per condition and per participant.

\section{Results}

A test for the significance of the difference between the means of two correlated samples was used to analyse the test results. This means of analysis was chosen because each student bivariate is logically linked: it is reasonable to assume that subjects cannot be both mastery-oriented and performance-oriented and, accordingly, any score in each bivariate must positively or negatively affect the other. In other words, a high score on one orientation should be reflected in a low score on the other. Initially, each population (architecture, engineering) was analysed separately. The overall scores obtained by the students show strong effects 
in favour of performance orientation in the engineering students, while the scores obtained by the architecture students are more balanced; they reveal no effect in favour of either orientation.

Data Summary

\begin{tabular}{|c|c|c|c|}
\hline Values & $\mathrm{X}_{\mathrm{a}}$ & $\mathrm{X}_{\mathrm{b}}$ & $\mathrm{X}_{\mathrm{a}}-\mathrm{X}_{\mathrm{b}}$ \\
\hline $\mathrm{n}$ & 141 & 141 & 141 \\
\hline sum & 1651.75 & 1423.25 & 228.5 \\
\hline mean & 11.7145 & 10.094 & 1.6206 \\
\hline sum-sq & 21391.0625 & 15171.9375 & 2393.625 \\
\hline SS & 2041.5727 & 805.6924 & 2023.3254 \\
\hline variance & 14.5827 & 5.7549 & 14.4523 \\
\hline st Dev & 3.8187 & 2.3989 & 3.8016 \\
\hline
\end{tabular}

Variances and standard deviations are calculated with denominator $=\mathrm{N}-1$

\section{Results}

\begin{tabular}{|c|c|c|}
\hline Mean $_{\mathrm{a}}-$ Mean $_{\mathrm{b}}$ & $\mathrm{t}$ & $\mathrm{df}$ \\
\hline 1.6206 & 5.0600 & 140 \\
\hline
\end{tabular}

\begin{tabular}{|c|c|c|}
\hline \multirow{2}{*}{$\mathrm{P}$} & one-tailed & $<.0001$ \\
\cline { 2 - 3 } & two-tailed & $<.0001$ \\
\hline
\end{tabular}

Table 1.1. - Engineering students $(n=141)$.

\section{Data Summary}

\begin{tabular}{|c|c|c|c|}
\hline Values & $\mathrm{X}_{\mathrm{a}}$ & $\mathrm{X}_{\mathrm{b}}$ & $\mathrm{X}_{\mathrm{a}}-\mathrm{X}_{\mathrm{b}}$ \\
\hline $\mathrm{n}$ & 118 & 118 & 118 \\
\hline sum & 1080.5 & 1100.1999 & 19.6999 \\
\hline mean & 9.1568 & 9.3237 & -0.1696 \\
\hline sum-sq & 10586.25 & 11506.9 & 1190.95 \\
\hline $\mathrm{SS}$ & 692.3496 & 1248.9336 & 1187.6611 \\
\hline variance & 5.9175 & 10.6746 & 10.1509 \\
\hline st Dev & 2.4326 & 3.2672 & 3.1861 \\
\hline
\end{tabular}

Variances and standard deviations are calculated with denominator $=\mathrm{N}-1$ 


\section{Results}

\begin{tabular}{|c|c|c|}
\hline Mean $_{\mathrm{a}}-$ Mean $_{\mathrm{b}}$ & $\mathrm{t}$ & $\mathrm{df}$ \\
\hline-0.1669 & -0.57 & 117 \\
\hline
\end{tabular}

\begin{tabular}{|c|c|c|}
\hline \multirow{2}{*}{$\mathrm{P}$} & one-tailed & .2852095 \\
\cline { 2 - 3 } & two-tailed & .570419 \\
\hline
\end{tabular}

Table 1.2. - Architecture students $(n=118)$.

In the $X_{a}-X_{b}$ column, the absence of negative signs (Table 1.1) indicates that the subjects' score in condition one was on average better than in condition two, while a negative sign (Table 1.2) indicates the opposite. For architecture students, negative signs were greater in number due to lower performance orientation scores, suggesting that they have a tendency towards mastery orientation. However, the value of $p(t=0.57$, $p=.2852095 / .570419)$ strongly indicates an absence of statistical significance for these findings. In other words, it is impossible to conclude solely on the strength of the above values that the architecture students as a whole tend conclusively towards either orientation.

For engineering students, on the other hand, negative signs were not greater in number, with the overall scores suggesting they have a tendency towards performance orientation. This is supported by a $p$ value $(t=5.06, p=<.0001)$ that indicates significant statistical effects in favour of performance orientation in engineering students (Table 1.1).

Clearly, then, engineering students seem to be performance-oriented, while architecture students overall seem to tend more towards mastery orientation. This raises the question about individual orientations within each population: are the performance-oriented individuals among the architecture students more or less performance-oriented than the engineering students, and similarly for the mastery-oriented individuals? In an attempt to clarify this question a Two-Sample t-Test for Independent Samples, engineering/architecture comparison was carried out on the data. 


\section{Data Summary}

\begin{tabular}{|c|c|c|c|}
\hline Values & $\mathrm{X}_{\mathrm{a}}$ & $\mathrm{X}_{\mathrm{b}}$ & $\mathrm{X}_{\mathrm{a}}-\mathrm{X}_{\mathrm{b}}$ \\
\hline $\mathrm{n}$ & 141 & 118 & 259 \\
\hline$\sum \mathrm{x}$ & 1652 & 1080.5 & 2732.5 \\
\hline$\sum \mathrm{x}^{2}$ & 21398.375 & 10586.25 & 31984.625 \\
\hline $\mathrm{SS}$ & 2043.0275 & 692.3496 & 3156.2225 \\
\hline mean & 11.7163 & 9.1568 & 10.5502 \\
\hline
\end{tabular}

\section{Results}

\begin{tabular}{|c|c|c|}
\hline Mean $_{\mathrm{a}}-$ Mean $_{\mathrm{b}}$ & $\mathrm{t}$ & $\mathrm{df}$ \\
\hline 2.5595 & 6.29 & 257 \\
\hline
\end{tabular}

\begin{tabular}{|c|c|c|}
\hline \multirow{2}{*}{$\mathrm{P}$} & one-tailed & $<.0001$ \\
\cline { 2 - 3 } & two-tailed & $<.0001$ \\
\hline
\end{tabular}

Table 2.1. - Performance scores architecture x engineering.

\section{Data Summary}

\begin{tabular}{|c|c|c|c|}
\hline Values & $\mathrm{X}_{\mathrm{a}}$ & $\mathrm{X}_{\mathrm{b}}$ & $\mathrm{X}_{\mathrm{a}}-\mathrm{X}_{\mathrm{b}}$ \\
\hline $\mathrm{n}$ & 141 & 118 & 259 \\
\hline$\sum \mathrm{x}$ & 1423.25 & 1100.19999 & 2523.45 \\
\hline$\sum \mathrm{x}^{2}$ & 15171.9375 & 11506.9000 & 26678.8375 \\
\hline $\mathrm{SS}$ & 805.6924 & 1248.9336 & 2092.7375 \\
\hline mean & 10.094 & 9.3237 & 9.7431 \\
\hline
\end{tabular}

\section{Results}

\begin{tabular}{|c|c|c|}
\hline Mean $_{\mathrm{a}}-$ Mean $_{\mathrm{b}}$ & $\mathrm{t}$ & $\mathrm{df}$ \\
\hline 0.7702 & 2.18 & 257 \\
\hline
\end{tabular}

\begin{tabular}{|c|c|c|}
\hline \multirow{2}{*}{$\mathrm{P}$} & one-tailed & 0.0150825 \\
\cline { 2 - 3 } & two-tailed & 0.030165 \\
\hline
\end{tabular}

Table 2.2. - Mastery scores architecture x engineering.

An architecture/engineering comparison of performance scores yielded statistically significant effects: $t=6.29, p=<.0001$. The rela- 
tionship between the two sets of variables seems to indicate a stronger presence of performance orientation in one of the groups. As the previous analysis shows, this stronger presence is almost certainly to be found within the engineering population. The architecture/engineering comparison of mastery scores, on the other hand, yields somewhat more subdued effects $(t=2.18, p=0.0150825 / 0.030165)$. In other words, from a purely statistical point of view, neither population seems to be significantly more mastery-oriented than the other.

The implication of the above analyses is that the likelihood of the experimental result having come about through mere random variability is extremely limited (on the whole less than 5\%). We can be confident therefore, at the level of $95 \%$, that the observed results reflect something more than mere random variability. This "something more" seems to be a clear tendency in engineering students to be more performance-oriented than their architecture counterparts, as displayed by a difference between the effects of the two test conditions on the scores obtained by the two populations.

\section{Discussion}

The analysis presented in this investigation showed that the highachievement learners in the study tend to be performance-oriented. The repercussions of such performance orientation are numerous and can contribute favourably to successful language learning as long as learning tasks are directly relevant to a given objective (Dörnyei, 2001). Among the repercussions of performance orientation is a tendency for positive attitudes (Midgley et al., 1996; Skaalvik, 1997; Pajares et al., 2000) and high levels of effort to prevail (Bouffard et al., 1995; Elliot and McGregor, 1999). An effort-related ethos corresponds to typical perceptions of engineering students in France. Language learners of this type are likely to deploy considerable effort until a specified objective is reached even though the strategies these learners develop are typically associated with extrinsic motivation and performance orientation.

Performance-orientation learning strategies typically suit undergraduates (Archer, 1994) possibly due to their superficial nature (Elliot et al., 1999). Observation of the engineering population in the investigation, who all were first-year students, revealed a greater preference for memorisation and learning vocabulary lists by rote. Such behaviour may clash with received language-learning axioms. In spite of this, these strategies may be considered positive because the techniques 
are well adapted to certain types of pedagogical material and to certain types of examination format like multiple-choice. Multiple-choice testing is believed (Harackiewicz et al., 2000) to appeal to the more superficial, as opposed to in-depth, understanding of subject content and, accordingly, to performance-oriented individuals. Interestingly, the engineering students in the investigation displayed greater success in the multiple-choice part of the test battery. They perceive it as a simpler means to gain points and, thereby, rewards. In other words, a multiplechoice format seems to bring about greater linguistic engagement in such language learners.

In spite of the possible pitfalls, the obvious choice when planning a language-learning curriculum for high-achievement learners is to set an objective that appeals to the learners' strategic preferences. In the institutions that participated in this investigation, all students are required to achieve a minimum score in an external certification. The mandatory nature of the requirement stimulates effort until the objective is reached. Although they can choose which external test to sit, most students (over 95\%) choose to sit the TOEIC test. It is felt that the format of this test corresponds to better their language-learning orientation. Also, in spite of personal feelings towards tests of this type, language teachers in the participating institutions generally agree that students are more focused and achieve higher language proficiency than in the past.

However, there can be a downside to performance-oriented learners. It is that of cheating. Cheating is taken to be a strong indicator of performance orientation and a lack of intrinsic interest in the subject being studied. Elliot and Harackiewicz (1996) uncovered a link between performance orientation and fraudulent success. They pointed at two factors, achievement motivation and fear of failure (both of which are characteristic of performance orientation), pressure learners into seeking success whatever the cost. In highly competitive environments where considerable emphasis is placed on performance, cheating is sometimes the only recourse open to some learners. Anderman et al. (1998) maintain that learners who perceive the learning situation as extrinsically focused or centred on performance are the ones most likely to resort to cheating. Students in engineering colleges have been known to cheat in external language tests. This behaviour points towards an extrinsic, utilitarian attitude towards language learning and is an unfortunate spin-off of performance orientation.

Finally, the architecture students were less performance-oriented than the engineering students. However, it could not be established 
clearly that this population was clearly mastery-oriented. This should come as no surprise: even though these students are very much involved in mastery-oriented activities in their day to day study curriculum (creativity and artistic flair being a considerable advantage), they are nevertheless a product of their educational culture. Even though studies in architecture may be perceived as less high-achievement than in engineering, the college, as an école, does aspire towards similar standing within the academic community. Consequently, in spite of the artistic leanings of architecture, it should come as no surprise to discover a strong presence of performance orientation in such students.

\section{Conclusion}

This study reported on French learners of largely lower intermediate language level studying in French institutions of higher education. One group of learners, the engineering students, was clearly more performance-oriented than the other. Their degree of performance orientation is such that their learning behaviour defies the accepted motivational paradigm, as perceived by many researchers and language instructors. The reason why these French learners' attitudes do not dovetail with the usual motivational expectations seems to be due to their learning culture, which differs in objectives and philosophies from Anglo-Saxon learning culture. Most previous research on language-learning motivation, and nearly all language-learning materials, come from Anglo Saxon countries. Both have been designed with learning in typically Anglo Saxon contexts in mind. It seems unwise on the part of language instructors in French institutions to carry into their classrooms typically Anglo-Saxon beliefs about learning and expect French learners to react as learners in Anglo Saxon contexts might.

In spite of the generally accepted (Anglo-Saxon) belief that intrinsic motivation and mastery performance are adaptive and, accordingly, desirable, it must not be forgotten that previous studies on motivation in language learners have nearly always taken as subject arts students who volunteer to participate the studies. Such studies invariably conclude that the learners involved are indeed intrinsically motivated. This is to be expected because of the learning culture, because of the learner type and because of the experimental context. No evidence has been found of previous studies involving high-achievement language learners (medical students, for example) in Anglo-Saxon countries. Should such studies be forthcoming, it is not unreasonable to surmise that their findings 
may well resemble those of the present study: it is possible that highachievers everywhere behave in a performance-oriented fashion for reasons to do with their very specific mind-set.

There seems to be sufficient reason to assume that adopting a performance-oriented approach would be justified in certain languagelearner contexts. When high-achievement language learners are involved, setting quantifiable goals such as success in external language tests clearly contributes to focusing the learners' attention, at least until the goal is achieved. In other words, a pedagogy organized around performance orientation and extrinsic motivation can in some circumstances generate an atmosphere favourable to language learning success. Whether or not this might be synonymous with the long-term cultivation of favourable dispositions towards the learning of foreign languages remains to be clarified.

More work obviously needs to be done on this theme. Further trials involving high-achievement learners, comparing them to learners in other learning environments, are plainly necessary. In the meantime, the present study will hopefully demonstrate that the obvious is not always the best course and that effective language-learning provision may depend on something more than merely attempting to implement the latest trends borrowed from elsewhere. It is hoped that this alternative framework will at least stimulate circumspection about past research on language-learning motivation in France and encourage future research to explore alternative constructs.

\section{BIBLIOGRAPHY}

Anderman E. M., Griesinger T., and Westerfield G. (1998): “Motivation and cheating during early adolescence", Journal of Educational Psychology, vol. 90, pp. 84-93.

Anderson L. and Krathwohl D. (2001): A Taxonomy for Learning, Teaching and Assessing: A Revision of Bloom's Taxonomy of Educational Objectives, New York, Longman.

ArCHer J. (1994): “Achievement goals as a measure of motivation in university students", Contemporary Educational Psychology, vol. 19, pp. 430-446.

Bouffard T., Boisvert J., Vezeau C., and Larouche C. (1995): “The impact of goal orientation on self-regulation and performance among college students", British Journal of Educational Psychology, vol. 65, pp. 317-329. 
Brown D. N. (2002): "Of men and mice: computer-based learning, choice and intrinsic motivation", Untele 2002: Proceedings to the $3^{\text {rd }}$ Colloquium, Compiegne, UTC.

Brown D. N. (2007): "Language Learner Motivation and the Role of Choice in ESP Listening Engagement", ASp, No. 51-52, pp. 159-177.

Covington M. (1992): Making the Grade, Cambridge, CUP.

DöRNYEI Z. (2001): Teaching and Researching Motivation, Harlow, Longman.

DwECK C. S. (1986): "Motivational processes affecting motivation", American Psychologist, vol. 41, pp. 1040-1048.

Elliot A. J. and McGregor H. A. (1999): "Test anxiety and the hierarchical model of approach and avoidance achievement motivation", Journal of Personality and Social Psychology, vol. 76, pp. 628-644.

Elliot A. J. and Harackiewicz J. M. (1996): "Approach and avoidance goals and intrinsic motivation: a mediational analysis", Journal of Personality and Social Psychology, vol. 70, pp. 461-475.

Harackiewicz J. M., Barron K. E., Tauer J. M., Carter S. M., and Elliot A. J. (2000): "Short-term and long-term consequences of achievement goals: predicting interest and performance over time", Journal of Educational Psychology, vol. 92, pp. 316-330.

Hofstede G. (2006): "Dimensionalizing Cultures: The Hofstede Model in Context" [Online], In W. J. Lonner, D. L. Dinnel, S. A. Hayes, and D. N. Sattler (eds), Online Readings in Psychology and Culture, Unit 2: Conceptual, Methodological and Ethical Issues in Psychology and Culture, Bellingham, Center for Cross-Cultural Research, Western Washington University. Online at <http://www.ac.wwu.edu/ culture/ readi ngs.htm>.

Midgley C., Kaplan A., and Middleton M. (2001): "Performance approach goals: good for what, for whom, under what circumstances and at what cost?", Journal of Educational Psychology, vol. 93, pp. 77-86.

Midgley C., Arunkumar R., and Urdan T. (1996): "If I don't do well tomorrow, there's a reason: predictors of adolescents' use of academic self-handicapping behaviour", Journal of Educational Psychology, vol. 88, pp. 423-434.

Pajares F., Britner S., and Valiente G. (2000): "Relationship between achievement goals and self-beliefs of middle-school students in writing and science", Contemporary Educational Psychology, vol. 25, pp. 406-422.

Ryan R. M. and Deci E. L. (2000): "Self-determination theory and the facilitation of intrinsic motivation, social development and well-being", American Psychologist, vol. 55, pp. 68-78. 
SkaAlviK E. M. (1997): "Self-enhancing and self-defeating ego orientation: relations with task and avoidance orientation, achievement, selfperceptions and anxiety", Journal of Educational Psychology, vol. 89, pp. 71-81.

\section{APPENDIX}

(selected and abridged examples from the test battery)

\section{Examples of Restrictive/Rigid Exercises}

Exercise 1: Errors - Find the mistake ( $a, b, c$ or $d$ ) in each sentence.

1. Australia does ${ }^{\mathrm{A}}$ not accept $\underline{a s}^{\mathrm{B}}$ many immigrants as they ${ }^{\mathrm{C}}$ used to $\underline{\mathrm{t}}^{\mathrm{D}}$.

2. You should drive little $\underline{\mathrm{A}}^{\mathrm{A}}$ faster if you want $\underline{\mathrm{us}}^{\mathrm{B}} \underline{\underline{t o}}^{\mathrm{C}}$ arrive before ${ }^{\mathrm{D}}$ midnight.

3. The boss is expected ${ }^{A}$ to know everything, ${ }^{\mathrm{B}}$ although anybody ${ }^{\mathrm{C}}$ knows $^{\mathrm{D}}$ everything.

Exercise 2: Verbs and prepositions - Complete each sentence by using one word from list A and one word from list B.

1. If you ...... only ...... technology, eventually you'll have problems.

2. I suggest you ........... our offer tonight and tell me about your decision tomorrow.

3. You should also ...... your company ...... the possibility of fraud.

Exercise 3: Grammar/Vocab - Decide which is the best choice among $a, b, c$ or $d$.

1. Due to great demand, we are moving our convention to a larger ...... so everyone who wants to join us can attend.
a exhibition
b venue
c lecture
d course

2. The market value of commodities to availability but now it seems to be the only regulating factor.
a didn't used to be linked
b didn't used to be link
c didn't use to be linked
d didn't used to being linked 
3. If you have an employment contract or a union agreement, it probably states how much ...... you should give if you want to quit your job.
a leave
b incentive
c head
d notice

\section{Examples of Open/Flexible Exercises}

Exercise 1: Vocabulary - Complete these sentences with one or two words.

1. Several conferences were taking place in the city at the same time, so most of the hotels were

2. During business trips, does our ...... cover taxi fares or are we allowed public transport only?

3. A trade ...... is organised every year at the Parc d'Expositions.

Exercise 2: Grammar - Complete each sentence with an appropriate present tense.

1. She ..... her lawyers at the airport tomorrow morning.

2. This book ...... to me. My name is written on the cover.

3 . He never ...... the table when he has finished his breakfast.

Exercise 3: Gap-fill - Complete each gap with one word.

Twenty years ago, there were only a (1) ...... legal translators and they were employed to translate complicated text for contracts or terms and conditions. Today, (2) ..... is a rapidly expanding profession and legal translators are in great demand. They are now involved (3) ...... producing all kinds of documentation, from court decisions (4) ...... international arrest warrants. 